\title{
Reduced intensity treatment in early-stage Hodgkin's lymphoma
}

This article was published in the following Dove Press journal:

Blood and Lymphatic Cancer:Targets and Therapy

24 November 2011

Number of times this article has been viewed

\section{Prathima Prodduturi James O Armitage}

University of Nebraska Medical Center, Omaha, NE, USA
Correspondence: James O Armitage University of Nebraska Medical Center, 42nd and Emile St, Omaha,

NE 68198-7680, USA

$\mathrm{Tel}+\mathrm{I} 4025597290$

$\mathrm{Fax}+\mathrm{I}$ 402-559-8597

Email joarmita@umc.edu

\begin{abstract}
Early-stage Hodgkin's lymphoma which includes patients with Ann Arbor stages I or II, accounts for more than $50 \%$ of all cases of the illness and is curable in a high proportion of patients. Long-term follow-up has shown that the mortality in favorable-risk patients with early-stage Hodgkin's lymphoma is exceeded by other causes including secondary malignancies and cardiac disease. Over the decades the treatment paradigm in Hodgkin's lymphoma has evolved from extended field radiotherapy to combined modality therapy using involved field radiotherapy to using chemotherapy alone. The data on long-term complications from using low dose and limited field radiation therapy is still awaited since we know that most of the secondary malignancies occur late (ie, more than 10 years after the treatment). By changing the chemotherapy regimens from mechlorethamine, vincristine, procarbazine, prednisone (MOPP) to doxorubicin, bleomycin, vinblastine, and dacarbazine (ABVD) the incidence of infertility and leukemia has been reduced. Since the late toxicity was high with radiotherapy, recent studies have focused on using chemotherapy alone. The results of interim positron emission tomography (PET) scans after two cycles of chemotherapy are being tested to see whether minimizing therapy in rapidly-responding patients will still maintain excellent cure rates. Here, we have reviewed some of the important clinical trials in early-stage Hodgkin's lymphoma and focus on some of the recent trials emphasizing reduced intensity treatment in early-stage Hodgkin's lymphoma.
\end{abstract}

Keywords: Hodgkin's lymphoma, treatment, early-stage, intensity, mortality

\section{Introduction}

Hodgkin's lymphoma was first described by Thomas Hodgkin in the 1830s in a manuscript titled "Some Morbid Appearances of the Absorbent Glands and Spleen". While it was once considered an incurable and fatal disease it is now one of the most curable malignancies. The efficacy of treatment has improved considerably in the last three decades. The possibility of curing patients with Hodgkin's lymphoma was first presented by Dr Vera Peters from Canada at the International Congress of Radiology meeting in Mexico City. Her data suggested a cure rate of $60 \%$ in patients with localized disease with a median survival of 8-11 years in patients with early-stage Hodgkin's lymphoma. Subsequent studies using linear accelerators in laparotomy-staged patients treated with extensive subtotal nodal radiation therapy showed 10 year relapse-free survival as high as $70 \%-80 \%$ for laparotomy-proven early-stage Hodgkin's lymphoma. ${ }^{1,2}$ However, the treatment was associated with an increased risk of heart disease, pulmonary toxicity, and secondary malignancies. Later, combined modality therapy with chemotherapy and radiation therapy was used which avoided staging laparotomy and splenectomy. 
Decreasing the field size and dose of radiation therapy reduced the risk of secondary malignancies and other organ damage. Initially chemotherapy was given after radiation and showed lower relapse rates. Later, radiation therapy was added as an adjuvant therapy to initial chemotherapy. Patients treated with combined modality therapy had better freedom from treatment failure but there was generally no difference in overall survival (Table 1). Currently, clinical trials are focusing on using the least amount of chemotherapy and radiation therapy possible without compromising cure rates. Recent studies have shown that chemotherapy alone could achieve excellent complete response rates. The results of interim positron emission tomography (PET) scans after two cycles of chemotherapy are being examined to see whether minimizing therapy in rapidly-responding patients will still maintain excellent cure rates..$^{3-5}$

Early-stage Hodgkin's lymphoma which includes patients with Ann Arbor stages I or II, accounts for more than 50\% of all cases of the illness. On the basis of clinical staging and risk factors, patients are divided into early favorable stage I and II without risk factors and early unfavorable stage I/II with risk factors. Risk factors differentiating between favorable and unfavorable categories vary among different American and European cooperative groups and include the presence of systemic symptoms (unexplained fevers $>38^{\circ} \mathrm{C}$, drenching night sweats or weight loss $>10 \%$ of body weight), a large mediastinal mass, bulky disease, high erythrocyte sedimentation rate $\geq 50$, an increase in the number of nodal sites involved, and older age. ${ }^{6}$ Treatment regimens are frequently different for favorable and unfavorable presentations.

Here, we review some of the important clinical trials in early-stage Hodgkin's lymphoma and focus on some of the recent trials emphasizing reduced intensity treatment in selected early-stage patients.

\section{Radiation therapy as the primary treatment}

For decades, radiation therapy was the standard treatment for early-stage Hodgkin's lymphoma. Extended field radiation therapy was the standard treatment in pathologically staged patients which included staging laparotomy and splenectomy. Although it was possible to achieve good results with radiation therapy alone, the relapse rates were as high as $20 \%-30 \%$. Extended field radiation therapy was found to be associated with an increased risk of secondary malignancies and cardiac disease. In trials (see Table 2) done using mantle irradiation alone, the 10-year relapse-free survival rates were about $70 \%$. The studies which compared extended field radiotherapy (EFRT) to involved field radiotherapy (IFRT) found no difference in cure rates or overall survival. ${ }^{7-9}$ The EORTC H8F trial showed that combined modality therapy using few cycles of chemotherapy with involved field radiation therapy resulted in better outcomes compared to

Table I Trials of combined-modality treatment in early-stage Hodgkin's lymphoma

\begin{tabular}{|c|c|c|c|c|}
\hline Author & Treatment & $\begin{array}{l}\text { Median follow-up } \\
\text { (years) }\end{array}$ & $\begin{array}{l}\text { Outcome } \\
\text { (FFP or PFS \%) }\end{array}$ & $\begin{array}{l}\text { Overall } \\
\text { survival (\%) }\end{array}$ \\
\hline \multirow[t]{2}{*}{ EORTC H7 F'3 } & EBVPX6+IFRT & 9.0 & 88 at 10 years & 92 at 10 years \\
\hline & STNI & & 78 at 10 years & 92 at 10 years \\
\hline \multirow[t]{5}{*}{ Bonadonna et $\mathrm{al}^{7}$} & $4 \times A B V D+I F R T$ & 9.7 & 94 at 12 years & 94 at 12 years \\
\hline & $36-40$ Gy & 9.7 & 93 at 12 years & 96 at 12 years \\
\hline & $4 \times A B V D+S N R T$ & & & \\
\hline & 36-40 Gy (involved sites) + & & & \\
\hline & 30.6 Gy (uninvolved sites) & & & \\
\hline \multirow[t]{3}{*}{ GHSG HD $7^{14}$} & $2 \times A B V D+E F R T$ & & & \\
\hline & 30 Gy EF+I0 Gy IF & 7.0 & 88 at 7 years & 94 at 7 years \\
\hline & $2 \times A B V D$ & & 67 at 7 years & 92 at 7 years \\
\hline \multirow[t]{2}{*}{ EORTC H9 F"I } & EBVPX6+IF 36 Gy & 4.0 & 87 at 4 years & 98 at 4 years \\
\hline & EBVPX6+IF 20 Gy & & 84 at 4 years & 98 at 4 years \\
\hline \multirow[t]{2}{*}{ EORTC H8 F } & MOPP-ABV+IFRT & 7.8 & 98 at 5 years & 97 at 10 years \\
\hline & STNI & & 74 at 5 years & 92 at 10 years \\
\hline \multirow[t]{4}{*}{ GHSG HD $10^{10}$} & $4 \times A B V D+I F R T 30$ Gy & 7.5 & 93 at 5 years & 97 at 5 years \\
\hline & $4 \times A B V D+I F R T 20$ Gy & 7.5 & 93 at 5 years & 97 at 5 years \\
\hline & $2 \times A B V D+I F R T 30$ Gy & 7.5 & 91 at 5 years & 97 at 5 years \\
\hline & $2 \times A B V D+I F R T 20$ Gy & 7.5 & 91 at 5 years & 97 at 5 years \\
\hline
\end{tabular}

Abbreviations: ABVD, doxorubicin, bleomycin, vinblastine and dacarbazine; MOPP, mechlorethamine, vincristine, procarbazine, prednisone; EBVP, epirubicin, bleomycin, vinblastine, and prednisone; IFRT, involved-field radiotherapy; EFRT, external field radiotherapy; STNI, subtotal nodal radiotherapy; FFP, freedom from progression; PFS, progression free survival. 
Table 2 Trials of radiation therapy alone in early-stage Hodgkin's lymphoma

\begin{tabular}{|c|c|c|c|c|}
\hline Author & Treatment & $\begin{array}{l}\text { Median follow-up } \\
\text { (years) }\end{array}$ & $\begin{array}{l}\text { Outcome } \\
\text { (FFP or PFS \%) }\end{array}$ & $\begin{array}{l}\text { Overall } \\
\text { survival (\%) }\end{array}$ \\
\hline \multirow[t]{2}{*}{ Liao et $\mathrm{al}^{53}$} & Mantle irradiation & 12.2 & 75.3 at 10 years & 87.6 at 10 years \\
\hline & & & 74.2 at 20 years & 65.3 at 20 years \\
\hline Backstrand et $\mathrm{a}^{54}$ & Mantle irradiation & 5.1 & 86 at 5 years & 100 at 5 years \\
\hline Mauch et a $\left.\right|^{55}$ & Mantle irradiation & 2.6 & 83 at 4 years & 100 at 4 years \\
\hline Zanini et $\mathrm{al}^{56}$ & Subtotal nodal irradiation & 6.5 & 80 at 7 years & 93 at 7 years \\
\hline Brusamolino et $\mathrm{al}^{57}$ & Extended mantle or subtotal nodal irradiation & 10.0 & 62 at 10 years & 94 at 10 years \\
\hline \multirow[t]{2}{*}{$\mathrm{Ng}$ et $\mathrm{al}^{58}$} & Mantle irradiation & 9.0 & 86 at 5 years & 98.2 at 10 years \\
\hline & & & 84.7 at 10 years & \\
\hline
\end{tabular}

Note: $94 \%$ was reported as the complete remission rate.

Abbreviations: FFP, freedom from progression; PFS, progression free survival.

subtotal nodal radiation therapy. ${ }^{14}$ Recently published data from the GHSG HD $10^{10}$ and the EORTC $\mathrm{H}^{2} \mathrm{~F}^{11}$ trials have shown that reducing the dose of radiation therapy has no impact on outcome in patients with favorable early-stage Hodgkin's lymphoma. Campbell et al published their data on involved-nodal radiation therapy (INRT) in limited-stage Hodgkin's lymphoma. According to their analysis, INRT was safe and there was no increase in the risk of locoregional relapse. With the newer radiation techniques we might be able to see a reduced incidence of toxicity. ${ }^{12}$

\section{Combined modality therapy}

Since relapse rates were higher than desirable after treatment with radiation therapy alone, and radiation was associated with long-term side effects, clinical trials have focused on combined modality therapy using abbreviated chemotherapy with reduced radiation fields (Table 2).

In the EORTC $\mathrm{H} 7$ trial, patients with clinically staged IA or IIA disease with favorable risk factors were randomized to EBVP (epirubicin, bleomycin, vinblastine, prednisone) plus IFRT vs subtotal lymphoid irradiation. At 6 years, the relapse-free survival was significantly better in patients allocated to chemotherapy plus IFRT compared to subtotal lymphoid irradiation $(92 \%$ vs $81 \%, P<0.004)$ and there was no difference in overall survival. ${ }^{13}$

Bonadonna et al conducted a study comparing doxorubicin, bleomycin, vinblastine, and dacarbazine (ABVD) plus subtotal nodal irradiation vs IFRT in early-stage Hodgkin's lymphoma. They found no statistically significant difference between these two groups in terms of overall survival, complete remission rates, and freedom from progression rates after 12 years of follow-up. ${ }^{7}$

The German Hodgkin Study Group (GHSG) HD7 trial compared extended-field radiotherapy alone with two cycles of ABVD followed by extended field radiation therapy in patients with early-stage favorable Hodgkin's lymphoma.
After 87 months of follow-up they reported that combined modality treatment consisting of two cycles of ABVD plus EFRT was more effective than EFRT alone with regard to freedom from treatment failure but there was no difference in complete response rate and overall survival. ${ }^{14}$

Similarly, the EORTC-GELA H8 trial showed that in patients with stage I or II Hodgkin's lymphoma with favorable prognostic features (H8-F trial), chemotherapy using mechlorethamine, vincristine, procarbazine, prednisone (MOPP)-ABV with IFRT had a higher 5-year event-free survival rate compared to chemotherapy with EFRT ( $98 \%$ vs $74 \%, P<0.001)$. The 10 -year survival rate was $97 \%$ vs $92 \%$ for patients allocated to MOPP-ABV plus IFRT versus MOPP-ABV alone, respectively $(P<0.001) .{ }^{8}$

The recent EORTC/GELA H9 F trial for patients with favorable Hodgkin's lymphoma evaluated six cycles of epirubicin, bleomycin, vinblastine, and prednisone (EBVP) followed by IFRT of either 36 or 20 Gy. The 4-year eventfree survival rates were $88 \%$ and $85 \%$ for patients allocated to EBVP plus IFRT of 36 Gy versus EBVP plus IFRT of $20 \mathrm{~Gy}$, respectively. The chemotherapy-alone arm with six cycles of EBVP with no radiation was closed early because of an excessive relapse rate. ${ }^{13}$

A study by Engert et $\mathrm{al}^{10}$ in patients with early-stage Hodgkin's lymphoma with favorable risk factors, found that treatment with two cycles of ABVD and 20 Gy radiation therapy showed similar freedom from treatment failure and overall survival compared to four cycles of ABVD and $30 \mathrm{~Gy}$ radiation therapy, with less acute toxicity. In patients with early-stage Hodgkin's lymphoma with unfavorable features, four cycles of ABVD + 20 Gy of IFRT was inferior to four cycles of ABVD + $30 \mathrm{~Gy}^{15}$

Another study conducted by the German Hodgkin Study Group HD8 showed that in patients with early-stage Hodgkin's lymphoma with unfavorable features, IFRT was equally effective in terms of overall survival and freedom 
from treatment failure and less toxic compared with EFRT after four cycles of chemotherapy cyclophosphamide, vincristine, procarbazine, and prednisone/doxorubicin, bleomycin, vinblastine, and dacarbazine (COPP+ABVD) ${ }^{16}$

\section{Chemotherapy alone for early-stage Hodgkin's lymphoma}

In the 1970s, physicians in Uganda treated early-stage Hodgkin's lymphoma patients with chemotherapy alone, since radiation therapy facilities were unavailable to them, and found surprisingly high response rates. ${ }^{16,17}$ A study conducted by Biti et al comparing MOPP with EFRT in stage I-IIA patients did not show any statistically significant difference in terms of overall survival or any other outcome at 5-year follow-up (Table 3). ${ }^{18}$ An 8-year follow-up in the same study showed that the patients allocated to radiation therapy had significantly longer survival compared to the chemotherapy group $(93 \%$ vs $56 \%, P<0.001)$ but the freedom from progression and the relapse-free survival rates were similar (76\% vs $64 \%$ and $70 \%$ vs $71 \%$, respectively).

Longo et al reported that MOPP chemotherapy was at least as effective as radiation therapy in the treatment of patients with early-stage Hodgkin's lymphoma. In patients with B symptoms, one to three sites of disease, normal erythrocyte sedimentation rate, and stage II disease, there was no significant difference between MOPP and radiation therapy. However, in patients with massive mediastinal disease, stage IIIA disease, elevated erythrocyte sedimentation rate, or four or more sites of disease, chemotherapy was superior to radiation therapy. ${ }^{19}$ At the 25 -year follow-up, disease-free survival and overall survival was $87 \%$ vs $63 \%$ and $81 \%$ vs $63 \%$ in the chemotherapy arm compared to the radiation arm, respectively. ${ }^{20}$

Straus et al described the results of a single-institution randomized trial of $A B V D$ plus radiation therapy vs $A B V D$ alone in patients with early-stage non-bulky Hodgkin's lymphoma, in which the 5-year survival was not significantly different ( $97 \%$ vs $90 \%$, respectively) between the two arms. ${ }^{21}$ This study also included patients with stage IIIA disease.

A study conducted by National Cancer Institute of Canada Clinical Trials Group (NCIC CTG) and the Eastern Cooperative Oncology Group in patients with early-stage Hodgkin's lymphoma compared ABVD chemotherapy to subtotal nodal radiation in patients with favorable risk features. The study included 399 evaluable patients. Patients were randomized to four to six cycles of ABVD or to treatment that included radiation therapy. There was no difference in overall survival but the 5-year freedom from disease progression was superior in patients randomized to radiation therapy compared to chemotherapy alone ( $93 \%$ vs $87 \%$, respectively, $P=0.006){ }^{22}$ At a median follow-up of about 4 years, patients randomized to chemotherapy alone had eight secondary cancers or cardiovascular events compared to 18 in patients randomized to radiation treatment arm.

A retrospective long-term follow-up study conducted by Olcese et al showed that the addition of radiotherapy

Table 3 Trials of chemotherapy alone in early-stage Hodgkin's lymphoma

\begin{tabular}{|c|c|c|c|c|}
\hline Author & Treatment & $\begin{array}{l}\text { Median follow-up } \\
\text { in years }\end{array}$ & $\begin{array}{l}\text { Outcome } \\
\text { (FFP or PFS \%) }\end{array}$ & $\begin{array}{l}\text { Overall survival } \\
\text { rate }(\%)\end{array}$ \\
\hline \multirow[t]{2}{*}{ Biti et al ${ }^{18}$} & $6 \times$ MOPP & 5.0 & 64 at 8 years & 56 at 8 years \\
\hline & EFRT & & 76 at 8 years & 93 at 8 years \\
\hline \multirow[t]{2}{*}{ Longo et al ${ }^{19,20}$} & MOPP & 25.0 & 83 at 25 years & 81 at 25 years \\
\hline & XRT & & 59 at 25 years & 63 at 25 years \\
\hline \multirow[t]{2}{*}{ Straus et $\mathrm{a}^{21}$} & $6 \times A B V D$ & 5.6 & 81 at 5 years & 90 at 5 years \\
\hline & $6 \times A B V D+I F R T$ or modified EFRT & & 86 at 5 years & 97 at 5 years \\
\hline \multirow[t]{2}{*}{ Meyer at a ${ }^{22}$} & $4-6 \times A B V D$ & 4.2 & 88 at 5 years & 97 at 5 years \\
\hline & SNRT & & 87 at 5 years & 100 at 5 years \\
\hline Rueda Dominguez et $\mathrm{a}^{42}$ & $6 \times A B V D$ & 6.5 & 88 at 7 years & 97 at 7 years \\
\hline \multirow[t]{2}{*}{ Olcese et $\mathrm{a}^{23}$} & $A B V D$ & 5.0 & 83 at 4 years & 95 at 4 years \\
\hline & $\begin{array}{l}\text { ABVD or Stanford V+ } \\
\text { EFRT OR IFRT }\end{array}$ & & 80 at 4 years & 82 at 4 years \\
\hline Canellos et $\mathrm{al}^{24}$ & $4-6 \times A B V D$ & 5.0 & 92 at 5 years & 100 at 5 years \\
\hline \multirow[t]{2}{*}{ Laskar et al ${ }^{48}$} & ABVD+IFRT & 5.3 & 97 at 8 years & 100 at 8 years \\
\hline & $A B V D$ & & 94 at 8 years & 98 at 8 years \\
\hline
\end{tabular}

Note: In this study, I3\% of patients had stage IIIA Hodgkin's lymphoma.

Abbreviations: ABVD, doxorubicin, bleomycin, vinblastine and dacarbazine; MOPP, mechlorethamine, vincristine, procarbazine and prednisone; Stanford V, mechlorethamine, doxorubicin, etoposide, vincristine, vinblastine, bleomycin; IFRT, involved-field radiotherapy; EFRT, external field radiotherapy; XRT, radiotherapy; SNRT, subtotal nodal radiotherapy; FFP, freedom from progression; PFS, progression free survival. 
Table 4 Treatment-related toxicity in early-stage Hodgkin's lymphoma

\begin{tabular}{|c|c|c|c|c|}
\hline Type of treatment & Cardiac disease (RR) & Pulmonary toxicity (RR) & Solid tumors (RR) & Acute leukemia (RR) \\
\hline Extended field radiotherapy & $4.0-5.0^{41 \mathrm{a}}$ & $\begin{array}{l}5.0^{2} \\
18.0^{65}\end{array}$ & $\begin{array}{l}3.3^{59} \\
4.1^{60} \\
4.3^{61 b} \\
3.2^{62 c} \\
2.0^{63}\end{array}$ & $\begin{array}{l}25.5^{60} \\
3.1^{61} \\
9.9^{63}\end{array}$ \\
\hline Combined modality therapy & $5.0^{37}$ & $4.0^{37}$ & $2.4^{37}$ & $2.6-10.6^{40 d}$ \\
\hline & $3.5-6^{41 \mathrm{a}}$ & $30^{65}$ & $\begin{array}{l}1.5^{59} \\
9.75^{60} \\
5.8^{61 b} \\
1.4^{62 c} \\
1.9^{63}\end{array}$ & $\begin{array}{l}178.5^{60} \\
50.6^{61} \\
24.7^{63}\end{array}$ \\
\hline MOPP & & & & $\begin{array}{l}2.2^{37} \\
5.9^{64}\end{array}$ \\
\hline ABVD & $4.0^{22 \mathrm{e}}$ & $\begin{array}{l}18^{45} \\
15^{65}\end{array}$ & & $0.6^{37}$ \\
\hline
\end{tabular}

Notes: a Risk was measured in standardized incidence ratios (SIR); ${ }^{\mathrm{b} R R}$ of lung cancer only; ${ }^{\mathrm{C} R R}$ of breast cancer only; ${ }^{\mathrm{d}}$ risk was dependent on the number of chemotherapy

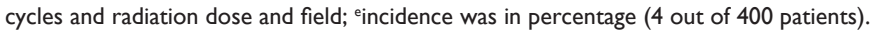

Abbreviations: ABVD, doxorubicin, belomycin, vinblastine, and dacarbazine; MOPP, mechlorethamine, vincristine, procarbazine, and prednisone; RR, relative risk.

to chemotherapy did not improve outcome of early-stage Hodgkin's lymphoma. ${ }^{23}$ The overall survival was $95 \%$ vs $82 \%$ $(P=0.47)$ in patients who received chemotherapy alone vs chemotherapy with radiotherapy, respectively. There was no increase in the incidence of second tumors in patients treated with chemotherapy alone whereas four secondary cancers were diagnosed in patients allocated to the combination therapy $\operatorname{arm}(5 \%, P=0.09){ }^{23}$

Recently Canellos et al have reported that in patients with early-stage non-bulky Hodgkin's lymphoma, chemotherapy alone with ABVD could achieve 100\% complete response rates and overall survival at 5 years. ${ }^{24}$

A study published by Laskar et al compared chemotherapy alone (ABVD) with chemotherapy with consolidation radiation (mainly IFRT). The 8 -year event-free survival (EFS) was $76 \%$ vs $88 \%(P=0.01)$ and overall survival was $89 \%$ vs $100 \%(P=0.002)$. The study showed an overall survival benefit in patients allocated to the radiation arm who had B symptoms, advanced stage, and who were less than 15 years of age. ${ }^{48}$

Most of the trials comparing chemotherapy alone to either combined modality therapy or radiotherapy alone did not have adequate power. Half of the trials have used MOPP chemotherapy which has been shown to be inferior to ABVD and/ or EFRT, which is no longer used. Nearly all of the studies were not adequately powered to detect a survival advantage and the long-term follow-up is not yet available. There are developing guidelines for selecting patients for treatment with chemotherapy alone. The National Comprehensive Cancer Network $(\mathrm{NCCN})^{25}$ guidelines used by many of the US oncologists recommend that for those patients who have asymptomatic, non-bulky, early-stage Hodgkin's lymphoma, physicians should prescribe ABVD alone (category 2B) or use a combined modality approach (category 1 ) consisting of either ABVD or the Stanford VERSUS chemotherapy regimen (mechlorethamine, doxorubicin, etoposide, vincristine, vinblastine, bleomycin) with IFRT.

\section{Long-term toxicity of chemotherapy and radiation therapy}

Treatment-related complications from radiation therapy have been reported in multiple studies (Table 4). They range from mild symptoms like dry mouth and dental caries to dangerous complications such as secondary malignancies, cardiac toxicity, and stroke. Breast cancer incidence is particularly high in women treated younger than 30 years of age, with an incidence of $30 \%-40 \%$ in the 25 years after the treatment. ${ }^{26,27}$ Mediastinal irradiation is known to cause cardiac disease. Cardiac complications of radiation continue to increase even after 20 years. The risk has been reported to be $6 \%$ at 10 years and $10 \%-20 \%$ at 20 years. ${ }^{28}$ The incidence of aortic valvular disease increases after 20 years compared to 10 years after radiation therapy. ${ }^{29}$ Cardiac toxicity could manifest as coronary heart disease, valvular heart disease, myocardial injury, restrictive cardiomyopathy (mostly associated with diastolic dysfunction), ${ }^{30}$ pericardial fibrosis, and conduction defects. With newer radiation techniques using reduced volume and dosing, systolic function seems to be better preserved. ${ }^{31,32}$ Hodgson et al have shown that by changing the radiation treatment from 35 Gy mantle field to 35 Gy involved field, the excess relative risks for breast and lung cancer can 
be reduced by $65 \%$. Changing the dose from 35 Gy IFRT to 20 Gy can reduce it by $40 \%$ more. $^{33}$

The risk of cardiac mortality is higher with higher doses of radiation and also higher with EFRT compared to involved-field radiotherapy. ${ }^{34,35}$ Patients who received more than 20 Gy of mediastinal therapy had an increased risk of CT-detected cardiac abnormalities. ${ }^{36}$ Travis et al noted that the incidence of breast cancer was increased in patients who received more than $40 \mathrm{~Gy}^{27}$

Gustavsson et a ${ }^{38}$ performed a systematic review of radiation therapy effects in patients with Hodgkin's lymphoma and included twelve randomized trials and two meta-analysis. He reported that after 15-20 years, the mortality from Hodgkin's lymphoma in early and intermediate stages is exceeded by other causes of death, mostly cardiac complications and secondary malignancies.

The frequency of late complications also depends on the type of treatment used. Using MOPP-like regimens the complications of infertility, myelodysplasia, acute leukemia, and lung cancer have been recognized. ${ }^{39,40}$ Alkylating agents are associated with an increased risk of acute myeloid leukemia and myelodysplasia. Doxorubicin has been associated with cardiac toxicity (ie, congestive heart failure) and the combination of radiation therapy and doxorubicin has an additive effect on cardiac toxicity. ${ }^{41} \mathrm{~A}$ few of the studies have shown that there is no increase in the incidence of secondary malignancies in patients treated with ABVD alone although the follow-up was short. ${ }^{42-44}$ Bleomycin has been associated with pulmonary toxicity and it was shown by Martin et $\mathrm{a}^{45}$ and Canellos et $\mathrm{a}^{46}$ that bleomycin pulmonary toxicity (BPT) was associated with decreased overall survival. BPT incidence was highest in patients older than 40 years and where granulocyte colony stimulating factor was used. ${ }^{45}$ Martin et al also reported that the omission of bleomycin had no impact on achieving complete remission, progression free survival, or overall survival..$^{45}$ Bleomycin pulmonary toxicity occurs in $10 \%-15 \%$ of patients when the cumulative dose exceeds $200 \mathrm{mg} / \mathrm{m}^{2}$. For lower cumulative doses early pulmonary toxicity occurs in 5\% of patients or less. The GHSG HD 13 trial will answer the question of whether bleomycin is an important component of the ABVD regimen. The interim analysis has shown that dacarbazine is an important component of ABVD. ${ }^{47}$

\section{Discussion}

Early-stage Hodgkin's lymphoma is curable in a high proportion of patients. Long-term follow-up has shown that the mortality in favorable risk patients with early-stage Hodgkin's lymphoma is exceeded by other causes including secondary malignancies and cardiac disease. ${ }^{6}$ At least in part to reduce these treatment related deaths, the treatment paradigm in Hodgkin's lymphoma has evolved from EFRT to combined modality therapy using IFRT to chemotherapy alone. The actual impact on long-term complications from using low dose and limited field radiation therapy is still awaited since we know that most of the secondary malignancies occur late (ie, more than 10 years after the treatment). Encouragingly, recently published data on involved-nodal radiation therapy (INRT) in limited-stage Hodgkin's lymphoma showed no increase in the risk of locoregional relapse compared to IFRT. ${ }^{12}$ Clinical trials using chemotherapy alone in patients with favorable risk, early-stage Hodgkin's lymphoma have shown excellent response rates with no difference in the overall survival rates in most of the trials, but the follow-up is relatively short. ${ }^{18-22,42,48}$

Currently, ongoing clinical trials are focusing on PETbased protocols for intensifying or de-intensifying treatment in patients with early-stage Hodgkin's lymphoma. Hutchings has shown that PET response after two or three cycles of chemotherapy to be an independent predictor of progression-free survival time and overall survival. ${ }^{3}$ The CALGB trial 50604 is assessing for PET response after two cycles of ABVD. ${ }^{49}$ Patients that are PET-negative receive four cycles of chemotherapy (ABVD) alone with no radiotherapy. Patients who are PET-positive receive additional BEACOPPesc (two cycles) followed by consolidative IFRT (30.6 Gy). The German HD16 (favorable stage I/II) is also focusing on PET response-guided radiotherapy. Patients on the first arm receive 30 Gy IFRT along with two cycles of ABVD regardless of PET response, while patients on the second arm receive IFRT only if PET-positive after two cycles of chemotherapy. ${ }^{50}$ Similarly the H 10 EORTC/GELA study is enrolling patients with stage I/II disease to ABVD 3-4 cycles and 30Gy INRT (involved node RT) vs PET-guided therapy. ${ }^{4}$ In the PET-guided arm, patients who are PET-negative receive an additional 1-2 courses of ABVD alone while patients who are PET-positive receive BEACOPPesc for two cycles and 30Gy INRT. ${ }^{51}$ A Phase III multicenter, open randomized trial (RAPID) conducted by NCRI Radiotherapy and Lymphoma Study Group is assessing the role of FDG-PET imaging in the treatment of early-stage Hodgkin's lymphoma. ${ }^{5}$ Patients who are PET-negative will be randomized to receive either IFRT or no further treatment. Individuals who are PET-positive will receive a fourth cycle of ABVD followed by IFRT.

A recently published Cochrane-based meta-analysis showed a hazard ratio of 0.40 (95\% confidence interval: $0.27-0.61$ ) for overall survival for patients receiving 
combined modality therapy compared to chemotherapy alone. ${ }^{52}$ Complete response rates were similar in both the groups. However, this meta-analysis also included patients with advanced stage and with B symptoms. The optimal treatment for patients with early-stage Hodgkin's lymphoma with either favorable or unfavorable characteristics is still not clear. Interpretation of recent studies is complicated by the fact that the cure rate is known in the first 5-10 years, but the mortality for treatment-related complications continues to increase for more than 20 years, particularly for patients who receive radiation. However, the use of reduced treatment intensity in rapidly responding, good prognosis patients offers the possibility to still achieve high cure rates with less long-term toxicity.

\section{Disclosure}

The authors report no conflicts of interest in this work.

\section{References}

1. Mauch P, Tarbell N, Weinstein H, et al. Stage IA and IIA supradiaphragmatic Hodgkin's disease: prognostic factors in surgically staged patients treated with mantle and paraaortic irradiation. $J$ Clin Oncol. 1988;6(10):1576-1583.

2. Cornbleet MA, Vitolo U, Ultmann JE, et al. Pathologic stages IA and IIA Hodgkin's disease: results of treatment with radiotherapy alone (1968-1980). J Clin Oncol. 1985;3(6):758-768.

3. Hutchings M, Loft A, Hansen M, et al. FDG-PET after two cycles of chemotherapy predicts treatment failure and progression-free survival in Hodgkin lymphoma. Blood. 2006;107(1):52-59.

4. AndreMO, Reman O, Fédérico M, etal.EORTC/GELAH10TRIAL.Blood. 209;114:Abst 97. Available from: http://abstracts.hematologylibrary. org/cgi/search?fulltext=EORTC\%3FGELA+H10+TRIAL\&sendit=En ter\&volume $=114 \&$ issue $=22 \&$ journalcode $=$ ashmtg.

5. Radford J, O'Doherty M, Barrington S, et al. Results of the 2 nd planned interim analysis of the RAPID Trial (involved field radiotherapy versus no further treatment) in patients with clinical stages $1 \mathrm{~A}$ and $2 \mathrm{~A}$ Hodgkin lymphoma and a 'negative' FDG-PET scan after 3 cycles ABVD. Blood. (ASH Annual Meeting Abstracts) 2008;112(11):Abst 369. Available from: http://abstracts.hematologylibrary.org/cgi/ search?fulltext=interim + analysis + of + the + RAPID+trial\&sendit=Ente r\&volume $=112 \&$ issue $=11 \&$ journalcode $=$ ashmtg .

6. Armitage JO. Early-stage Hodgkin's lymphoma. N Engl J Med. 2010; 363(7):653-662.

7. Bonadonna G, Bonfante V, Viviani S, Di Russo A, Villani F, Valagussa P. ABVD plus subtotal nodal versus involved-field radiotherapy in earlystage Hodgkin's disease: long-term results. J Clin Oncol. 2004;22(14): 2835-2841.

8. Heutte N, Flechtner HH, Mounier N, et al. Quality of life after successful treatment of early-stage hodgkin's lymphoma: 10-year follow-up of the EORTC-GELA H8 randomised controlled trial. Lancet Oncol. 2009;10(12):1160-1170.

9. Engert A, Schiller P, Josting A, et al. Involved-field radiotherapy is equally effective and less toxic compared with extended-field radiotherapy after four cycles of chemotherapy in patients with earlystage unfavorable Hodgkin's lymphoma: results of the HD8 trial of the German Hodgkin's Lymphoma Study Group. J Clin Oncol. 2003; 21(19):3601-3608.

10. Engert A, Plutschow A, Eich HT, et al. Reduced treatment intensity in patients with early-stage Hodgkin's lymphoma. N Engl J Med. 2010; 363(7):640-652.
11. Eghbali H, Brice GY, Creemers M, et al. EORTC lymphoma cooperative group H9F trial. ASH-2005/ Blood. 2005;106(11):240a, Abstr 813 and 814. Available from: http://online.haematologica.org/supplements/ Hematology_Education_2007.pdf.

12. Campbell BA, Voss N, Pickles T, et al. Involved-nodal radiation therapy as a component of combination therapy for limited-stage hodgkin's lymphoma: a question of field size. J Clin Oncol. 2008;26(32):5170-5174.

13. Noordijk EM, Carde P, Mandard AM, et al. Preliminary results of the EORTC-GPMC controlled clinical trial H7 in early-stage Hodgkin's disease. EORTC Lymphoma Cooperative Group. Groupe Pierre-etMarie-Curie. Ann Oncol. 1994;5 Suppl 2:107-112.

14. Engert A, Franklin J, Eich HT, et al. Two cycles of doxorubicin, bleomycin, vinblastine, and dacarbazine plus extended-field radiotherapy is superior to radiotherapy alone in early favorable Hodgkin's lymphoma: final results of the GHSG HD7 trial. J Clin Oncol. 2007;25(23): 3495-3502.

15. Eich HT, Diehl V, Gorgen H, et al. Intensified chemotherapy and dosereduced involved-field radiotherapy in patients with early unfavorable Hodgkin's lymphoma: final analysis of the german hodgkin study group HD11 trial. J Clin Oncol. 2010;28(27):4199-4206.

16. Olweny CL, Katongole-Mbidde E, Kiire C, Lwanga SK, Magrath I, Ziegler JL. Childhood Hodgkin's disease in Uganda: a ten year experience. Cancer. 1978;42(2):787-792.

17. Olweny CL, Ziegler JL, Berard CW, Templeton AC. Adult Hodgkin's disease in Uganda. Cancer. 1971;27(6):1295-1301.

18. Biti GP, Cimino G, Cartoni C, et al. Extended-field radiotherapy is superior to MOPP chemotherapy for the treatment of pathologic stage I-IIA Hodgkin's disease: eight-year update of an italian prospective randomized study. J Clin Oncol. 1992;10(3):378-382.

19. Longo DL, Glatstein E, Duffey PL, et al. Radiation therapy versus combination chemotherapy in the treatment of early-stage Hodgkin's disease: seven-year results of a prospective randomized trial. J Clin Oncol. 1991;9(6):906-917.

20. Longo DL, Glatstein E, Duffey PL, et al. A prospective trial of radiation alone vs combination chemotherapy alone for early-stage Hodgkin's disease: implications of 25 year follow-up to current combined modality therapy [abstract]. Blood. 2006;108(11):33a, Abst 98.

21. Straus DJ, Portlock CS, Qin J, et al. Results of a prospective randomized clinical trial of doxorubicin, bleomycin, vinblastine, and dacarbazine (ABVD) followed by radiation therapy (RT) versus ABVD alone for stages I, II, and IIIA nonbulky Hodgkin disease. Blood. 2004; 104(12):3483-3489.

22. Meyer RM, Gospodarowicz MK, Connors JM, et al. Randomized comparison of ABVD chemotherapy with a strategy that includes radiation therapy in patients with limited-stage hodgkin's lymphoma: National Cancer Institute of Canada Clinical Trials Group and the Eastern Cooperative Oncology Group. J Clin Oncol. 2005;23(21): 4634-4642.

23. Olcese F, Clavio M, Rossi E, et al. The addition of radiotherapy to chemotherapy does not improve outcome of early-stage Hodgkin's lymphoma patients: a retrospective long-term follow-up analysis of a regional Italian experience. Ann Hematol. 2009;88(9):855-861.

24. Canellos GP, Abramson JS, Fisher DC, LaCasce AS. Treatment of favorable, limited-stage Hodgkin's lymphoma with chemotherapy without consolidation by radiation therapy. J Clin Oncol. 2010;28(9): 1611-1615.

25. National Comprehensive Cancer Network. NCCN guidelines and clinical resources. Available from: http://www.nccn.org/clinical.asp.

26. Franklin J, Pluetschow A, Paus M, et al. Second malignancy risk associated with treatment of Hodgkin's lymphoma: meta-analysis of the randomised trials. Ann Oncol. 2006;17(12):1749-1760.

27. Travis LB, Hill D, Dores GM, et al. Cumulative absolute breast cancer risk for young women treated for Hodgkin lymphoma. J Natl Cancer Inst. 2005;97(19):1428-1437.

28. Gospodarowicz MK, Meyer RM. The management of patients with limited-stage classical Hodgkin lymphoma. Hematology Am Soc Hematol Educ Program. 2006:253-258. 
29. Heidenreich PA, Hancock SL, Lee BK, Mariscal CS, Schnittger I. Asymptomatic cardiac disease following mediastinal irradiation. $\mathrm{JAm}$ Coll Cardiol. 2003;42(4):743-749.

30. Lipshultz SE, Sallan SE. Cardiovascular abnormalities in longterm survivors of childhood malignancy. J Clin Oncol. 1993;11(7): 1199-1203.

31. Perrault DJ, Levy M, Herman JD, et al. Echocardiographic abnormalities following cardiac radiation. J Clin Oncol. 1985;3(4):546-551.

32. Burns RJ, Bar-Shlomo BZ, Druck MN, et al. Detection of radiation cardiomyopathy by gated radionuclide angiography. Am J Med. 1983; 74(2):297-302.

33. Hodgson DC, Koh ES, Tran TH, et al. Individualized estimates of second cancer risks after contemporary radiation therapy for Hodgkin lymphoma. Cancer. 2007;110(11):2576-2586.

34. Hancock SL, Tucker MA, Hoppe RT. Factors affecting late mortality from heart disease after treatment of hodgkin's disease. JAMA. 1993; 270(16):1949-1955.

35. Koh ES, Tran TH, Heydarian M, et al. A comparison of mantle versus involved-field radiotherapy for Hodgkin's lymphoma: reduction in normal tissue dose and second cancer risk. Radiat Oncol. 2007; 2:13.

36. Kupeli S, Hazirolan T, Varan A, et al. Evaluation of coronary artery disease by computed tomography angiography in patients treated for childhood Hodgkin's lymphoma. J Clin Oncol. 2010;28(6): $1025-1030$

37. Brusamolino E, Lunghi F, Orlandi E, et al. Treatment of early-stage Hodgkin's disease with four cycles of ABVD followed by adjuvant radiotherapy: analysis of efficacy and long-term toxicity. Haematologica. 2000;85(10):1032-1039.

38. Gustavsson A, Osterman B, Cavallin-Stahl E. A systematic overview of radiation therapy effects in Hodgkin's lymphoma. Acta Oncol. 2003; 42(5-6):589-604.

39. Blayney DW, Longo DL, Young RC, et al. Decreasing risk of leukemia with prolonged follow-up after chemotherapy and radiotherapy for Hodgkin's disease. N Engl J Med. 1987;316(12):710-714.

40. Andrieu JM, Ifrah N, Payen C, Fermanian J, Coscas Y, Flandrin G. Increased risk of secondary acute nonlymphocytic leukemia after extended-field radiation therapy combined with MOPP chemotherapy for Hodgkin's disease. J Clin Oncol. 1990;8(7):1148-1154.

41. Aleman BM, van den Belt-Dusebout AW, De Bruin ML, et al. Late cardiotoxicity after treatment for Hodgkin lymphoma. Blood. 2007; 109(5):1878-1886.

42. Rueda Dominguez A, Marquez A, Guma J, et al. Treatment of stage I and II Hodgkin's lymphoma with ABVD chemotherapy: results after 7 years of a prospective study. Ann Oncol. 2004;15(12):1798-1804.

43. Valagussa P, Santoro A, Fossati Bellani F, Franchi F, Banfi A, Bonadonna G. Absence of treatment-induced second neoplasms after ABVD in Hodgkin's disease. Blood. 1982;59(3):488-494.

44. Viviani S, Bonadonna G, Santoro A, et al. Alternating versus hybrid MOPP and ABVD combinations in advanced Hodgkin's disease: ten-year results. J Clin Oncol. 1996;14(5):1421-1430.

45. Martin WG, Ristow KM, Habermann TM, Colgan JP, Witzig TE, Ansell SM. Bleomycin pulmonary toxicity has a negative impact on the outcome of patients with Hodgkin's lymphoma. J Clin Oncol. 2005; 23(30):7614-7620.

46. Canellos GP, Duggan D, Johnson J, Niedzwiecki D. How important is bleomycin in the adriamycin + bleomycin + vinblastine + dacarbazine regimen? J Clin Oncol. 2004;22(8):1532-1533.

47. Borchmann P, Diehl V, Goergen H, et al. Dacarbazine is an essential component of ABVD in the treatment of early favourable Hodgkin lymphoma: results of the second interim analysis of the GHSG HD 13 trial [abstract]. Haematologica. 2010;95(Suppl 2):473, Abst 1146.

48. Laskar S, Gupta T, Vimal S, et al. Consolidation radiation after complete remission in hodgkin's disease following six cycles of doxorubicin, bleomycin, vinblastine, and dacarbazine chemotherapy: is there a need? J Clin Oncol. 2004;22(1):62-68.
49. Cancer and Leukemia Group B; National Cancer Institute (NCI). Chemotherapy Based on Positron Emission Tomography Scan in Treating Patients With Stage I or Stage II Hodgkin Lymphoma. In: ClinicalTrials.gov [Internet]. Bethesda, MD: National Library of Medicine (US). May 27, 2010 [Last updated on October 11, 2011]. Available at: http://clinicaltrials.gov/ct2/show/NCT01132807. NLM identifier: NCT01132807.

50. University of Cologne. HD16 for Early Stage Hodgkin Lymphoma. In: ClinicalTrials.gov [Internet]. Bethesda, MD: National Library of Medicine (US). August 8, 2008 [last updated on July 19, 2011]. Available from: http://clinicaltrials.gov/ct2/show/NCT00736320. NLM identifier: NCT00736320.

51. European Organization for Research and Treatment of Cancer EORTC; Groupe d'Etudes de Lymphomes de L'Adulte and Intergruppo Italiano Linfomi. Fludeoxyglucose F 18 PET Scan-Guided Therapy or Standard Therapy in Treating Patients With Previously Untreated Stage I or Stage II Hodgkin's Lymphoma. In: ClinicalTrials. gov [Internet]. Bethesda, MD: National Library of Medicine (US). February 8, 2007 [last updated on July 20, 2011]. Available from: http:/clinicaltrials.gov/ct2/show/NCT00433433. NLM identifier: NCT00433433.

52. Herbst C, Rehan FA, Skoetz N, et al. Chemotherapy alone versus chemotherapy plus radiotherapy for early-stage Hodgkin lymphoma. Cochrane Database Syst Rev. 2011;2:CD007110.

53. Liao Z, Ha CS, Vlachaki MT, et al. Mantle irradiation alone for pathologic stage I and II Hodgkin's disease: long-term follow-up and patterns of failure. Int J Radiat Oncol Biol Phys. 2001;50(4):971-977.

54. Backstrand KH, Ng AK, Takvorian RW, et al. Results of a prospective trial of mantle irradiation alone for selected patients with early-stage Hodgkin's disease. J Clin Oncol. 2001;19(3):736-741.

55. Mauch PM, Canellos GP, Shulman LN, et al. Mantle irradiation alone for selected patients with laparotomy-staged IA to IIA Hodgkin's disease: preliminary results of a prospective trial. J Clin Oncol. 1995; 13(4):947-952.

56. Zanini M, Viviani S, Santoro A, et al. Extended-field radiotherapy in favorable stage IA-IIA Hodgkin's disease (prognostic role of stage). Int J Radiat Oncol Biol Phys. 1994;30(4):813-819.

57. Brusamolino E, Lazzarino M, Orlandi E, et al. Early-stage Hodgkin's disease: long-term results with radiotherapy alone or combined radiotherapy and chemotherapy. Ann Oncol. 1994;5 Suppl 2:101-106.

58. Ng AK, Li S, Neuberg D, Fisher DC, et al. Long-term results of a prospective trial of mantle irradiation alone for early-stage Hodgkin's disease. Ann Oncol. 2006;17(11):1693-1697.

59. Salloum E, Doria R, Schubert W, et al. Second solid tumors in patients with Hodgkin's disease cured after radiation or chemotherapy plus adjuvant low-dose radiation. J Clin Oncol. 1996;14(9):2435-2443.

60. Mauch PM, Kalish LA, Marcus KC, et al. Second malignancies after treatment for laparotomy staged IA-IIIB Hodgkin's disease: long-term analysis of risk factors and outcome. Blood. 1996;87(9): $3625-3632$.

61. Van Leeuwen FE, Klokman WJ, Hagenbeek A, et al. Second cancer risk following Hodgkin's disease: a 20-year follow-up study. J Clin Oncol. 1994;12(2):312-325.

62. Travis LB, Hill DA, Dores GM, et al. Breast cancer following radiotherapy and chemotherapy among young women with Hodgkin disease. JAMA. 2003;290(4):465-475.

63. Dores GM, Metayer C, Curtis RE, et al. Second malignant neoplasms among long-term survivors of hodgkin's disease: a population-based evaluation over 25 years. J Clin Oncol. 2002;20(16):3484-3494.

64. Boivin JF, Hutchison GB, Zauber AG, et al. Incidence of second cancers in patients treated for Hodgkin's disease. J Natl Cancer Inst. 1995; 87(10):732-741.

65. Hirsch A, Vander Els N, Straus DJ, et al. Effect of ABVD chemotherapy with and without mantle or mediastinal irradiation on pulmonary function and symptoms in early-stage Hodgkin's disease. J Clin Oncol. 1996;14(4):1297-1305. 
66. Carde P, Hagenbeek A, Hayat M, et al. Clinical staging versus laparotomy and combined modality with MOPP versus ABVD in early-stage Hodgkin's disease: the H6 twin randomized trials from the European Organization for Research and Treatment of Cancer Lymphoma Cooperative Group. J Clin Oncol. 1993;11(11):2258-2272.

67. Bhatia S, Yasui Y, Robison LL, et al. High risk of subsequent neoplasms continues with extended follow-up of childhood Hodgkin's disease: report from the Late Effects Study Group. J Clin Oncol. 2003;21(23): 4386-4394.
68. van Leeuwen FE, Klokman WJ, Veer MB, et al. Long-term risk of second malignancy in survivors of Hodgkin's disease treated during adolescence or young adulthood. J Clin Oncol. 2000;18(3): $487-497$.

\section{Publish your work in this journal}

Blood and Lymphatic Cancer: Targets and Therapy is an international, peer-reviewed, open access journal focusing on blood and lymphatic cancer research, identification of therapeutic targets and the optimal use of preventative and integrated treatment interventions to achieve improved outcomes, enhanced survival and quality of life for the cancer patient. The manuscript management system is completely online and includes a very quick and fair peer-review system. Visit http://www.dovepress.com/testimonials.php to read real quotes from published authors.

Submit your manuscript here: http://www.dovepress.com/blood-and-lymphatic-cancer-targets-and-therapy-journal 